\title{
O DIREITO DOS ANIMAIS DE COMPANHIA
}

\author{
The right of companion animals \\ A compaixão pelos animais está intimamente ligada à bondade de caráter, e pode ser seguramente \\ afirmado que quem é cruel com os animais não pode ser um bom homem. \\ Arthur Schopenhauer
}

Recebido: 19.07.2018 | Aceito: 10.08.2018

\section{Deborah Regina Lambach Ferreira da Costa}

Graduada em direito pela Universidade Federal do Paraná em 1983. Mestre e doutora em direito civil comparado pela Pontificia Universidade Catolica de São Paulo. Professora de direito civil da Pontificia Universidade Catolica de São Paulo desde 1992. Procuradora do município de São Paulo. Email: deborahlambach@hotmail.com. Lattes: http://lattes.cnpq.br/1002193677066082

\section{Fabiano Montiani Ferreira}

Professor associado de oftalmologia veterinária e clínica médica de pequenos animais coordenador do programa de pós-graduação em ciências veterinárias departamento de medicina Veterinária Universidade Federal do Paraná. Lattes: http:/ / lattes.cnpq.br/8220825890706508

\begin{abstract}
Resumo
O presente artigo pretende discutir se as alterações havidas nos Códigos Civis suíço, francês, alemão, austríaco e português, no que diz respeito aos animais, devem ser incorporadas ao Código Civil brasileiro. Isso porque, nesses países, o Código Civil dispõe que os animais são seres sensíveis, regidos por lei especial e, portanto, não mais "objeto" de posse ou propriedade, reconhecendo-se o valor intrínseco que possuem, embora não se enquadrem na categoria de pessoa, "status" atribuído ao ser humano. De modo que, por não possuírem personalidade, pertenceriam a um terceiro gênero de classificação e, portanto, de regime jurídico. Há cada vez mais um consenso filosófico, social, cultural e jurídico de que o animal não-humano precisa ter reconhecida a sua natureza de ser vivo sensível, dotando-lhe o ordenamento jurídico de um verdadeiro Estatuto, não podendo mais ser considerado como simples peça de mobiliário. Na toada dessa evolução, os animais de companhia tem sido objeto de guarda compartilhada do casal ou dos conviventes quando do rompimento da comunhão de vida. No divórcio ou extinção da união estável, a tendência da jurisprudência atual não é partilhar o bem conforme o regime de bens, mas considerar os animais de companhia como seres sencientes, capazes de dar e retribuir afeto, parte integrante da família. O afeto que une os membros da família matrimonial, da união estável, homafetiva, monoparental, anaparental e eudemonista, se estende aos animais de companhia.
\end{abstract}

Palavras-chave: Animais. Bens. Seres sencientes. Animais de companhia. Aletração do Codigo Civil. Divórcio. Guarda compartilhada. Dano moral.

\section{Abstract}

This article intends to discuss if the changes occurred in the Civil Code of Switzerland, France, Germany, Austria and Portugal, concerning animals, should be incorporated in the Brazilian 
Civil Code. The reason is because in these countries, the Civil Code rules that animals are sentient beings, ruled by special laws, and therefore no longer in possession or property of its owner, recognizing the intrinsic value they possess, altough they have no personality, "status" attributed to human being. So that, because they do not have personality, they would belong to a third genre of classification and, therefore, of legal regime. There is a growing philosophical, social, cultural and juridical consensus that the nonhuman animal must have recognized its sensuous living nature, so they should have equal rights, and they can no longer be considered as a simple piece of furniture. In the toad of this evolution, companion animals have been the object of shared custody of the couple when marriage ends. In divorce or in stable union, the tendency of judicial decisions is not to share the good according to the marital property systems, but to consider pets as sentient beings, able to give and give back affection, as part of the Family. The affection that unites Family members, nuclear ones, single parent ones, extended Families, chidless ones, stepfamilies, and so on, is also the same affection that unites the Family members to its companion animals.

Keywords: Animals. Assets. Sentient beings. Pets. Changes in Civil Code. Divorce. Moral damage.

Sumário: 1. Direitos dos animais de companhia. Conceito e características. Alteração nos Códigos Civis da França, Suiça, Áustria, Alemanha e Portugal. O animal como ser senciente. Propriedade viva. Necessidade de mudança de paradigma com alteração do Codigo Civil brasileiro. Decisões jurisprudenciais no Direito de Familia reconhecendo novo status ao animal de companhia. Considerações finais.

Há uma famosa citação de René Descartes (1596-1650) que reflete exatamente a forma que os animais vêm sendo tratados pelo homem na sociedade moderna: "os animais são como robôs: eles não podem raciocinar ou sentir dor".

A criação de animais é uma característica tão antiga quanto a própria sociedade humana. Tal interação desempenha inúmeros papéis seja para o indivíduo, no círculo familiar ou num contexto social mais amplo. ${ }^{1}$

A relação entre o homem e os animais inicialmente era de predação, passando mais tarde para a domesticação. Entre os muitos papéis representados pelos animais estão os mais óbvios e conhecidos como produção de comida, vestimentas, companhia, proteção ou guarda, ou em funções de trabalho exercendo atividades específicas de serviço. ${ }^{2}$

Atualmente, a importância dos animais de companhia é tamanha para a sociedade que tranquilamente podemos classificá-la como incomensurável. A companhia de um animal vem cada vez mais sendo reconhecida como algo básico e importante. Não podemos esquecer que a primeira espécie domesticada pelo homem foi o cão (Canis familiaris) a partir do lobo (Canis lupus) ${ }^{3}$ com a finalidade explicita de fazer companhia e oferecer proteção. Ou seja, o homem primitivo se preocupou com estes aspectos para somente depois se preocupar em domesticar outros animais para produzir alimento. Em última análise, o cão foi criado pelo homem por meio de seleção artificial. Portanto, é inegável uma ligação de criadorcriatura do homem com os cães e, com isso, certo senso de responsabilidade.

Assim, o que caracteriza esses animais como sendo de companhia é o laço afetivo ou de proximidade ao núcleo de pessoas que eles se relacionam e as atividades, quando previstas, a serem executadas ou exercidas, além da responsabilidade legal atribuída. ${ }^{4}$ 
Os animais de companhia comprovadamente proporcionam melhoria da qualidade de vida dos seus responsáveis. Além de obviamente diminuírem os sentimentos de solidão, os animais de companhia proporcionam um estado de felicidade obtido pelo simples convívio, além de benefícios físicos e psíquicos que são objetivamente mensuráveis. ${ }^{5}$

Ocorre maior ativação do sistema de liberação de ocitocina pelo sistema nervoso central daquelas pessoas responsáveis pelo cuidado de animais companhia. Tal hormônio é capaz de aumentar sentimentos de bem-estar, compaixão, felicidade e ligação social. ${ }^{6}$

Ao que tudo indica o convívio de crianças com animais de estimação faz com que as mesmas se tornem mais afetivas, solidárias, sensíveis, com maior senso de responsabilidade, e faz ainda com que consigam entender melhor a morte. ${ }^{7}$ Adicionalmente, a presença do animal de estimação pode estimular também pessoas de mais idade a se movimentar, pessoas sedentárias e obesas a realizarem exercícios físicos.

Os animais ditos de companhia, portanto, seriam aqueles que prestariam de forma geral apoio emocional, tendo isso como objetivo especifico, aqueles como os quais se relacionam. O fato é que a maioria dos responsáveis acaba considerando seu animal de estimação como amigo ou até mesmo membro da família. ${ }^{8}$

\footnotetext{
"Não é à toa que falamos que nosso cachorro é mais manso e mais esperto; que nosso gato tem o pelo mais luzidio e a preguiça mais bonita e gostosa, e que nosso passarinho canta mais bonito e mais alto..." 9
}

Os animais mais populares são os cães, os gatos, pássaros e cavalos, mas também peixes, furões, coelhos, hamsters, porquinhos-da-índia, gerbilos, outros roedores, jabutis, serpentes, lagartos, outros répteis, ainda aves diversas e animais em geral tidos como de produção, como galináceos, suínos, bovinos, dentre outros, domésticos ou selvagens. Segundo a Associação Brasileira da Indústria de Produtos para Animais de Estimação (ABINPET), o Brasil apresenta a quarta maior população de animais de estimação do mundo, com aproximadamente 106 milhões, ficando somente atrás da China, Estados Unidos e Reino Unido. ${ }^{10}$

Em virtude dos benefícios de se cuidar de uma animal de companhia, uma formidável interação homem-animal foi se desenvolvendo ao longo dos anos, e a par disso, varias ideias e iniciativas começaram a surgir no sentido de se utilizar de animais para serviços ou como recurso terapêutico em hospitais ou centros especializados. ${ }^{11} \mathrm{O}$ animal de companhia para serviços é treinado para realizar tarefas que beneficiam indivíduos com deficiências incluindo as físicas, sensoriais, psiquiátricas, intelectuais ou outras mentais.

Os ordenamentos jurídicos de alguns países europeus, que moldaram inclusive nossa legislação civilista, evoluíram ao longo desses últimos anos, respondendo ao apelo de entidades protetoras dos animais, de ecologistas, de preceitos éticos, bioéticos e filosóficos, para atribuir aos animais um valor intrínseco, tendente a não mais considerá-los como coisa, pertecente à categoria de bens, mas como seres sensíveis, capazes de sentir dor e prazer.

Os Códigos Civis suíço, francês, alemão, austríaco e português alargaram a proteção jurídica na defesa dos interesses dos animais, em especial aos animais de companhia, sendo que em Portugal, o Projeto de Lei n. 173/XII/1 ${ }^{\text {a, }}$, que altera o Código Civil, objetivou dotar os animais de um estatuto jurídico, que reconheça aos animais não-humanos suas diferenças 
e natureza, quer frente aos animais humanos, quer frente ao tratamento dado às coisas inanimadas.

Assim, os animais são seres vivos e sencientes, podendo ser objeto de relações jurídicas e a sua proteção jurídica se opera por lei especial, aplicando-se o regime dos bens subsidiariamente.

A proteção jurídica dos animais, em especial dos animais de companhia, tem sido tema recorrente, sendo que sua importância denota uma evolução na defesa dos seus interesses.

As alterações legislativas dos Códigos Civis da Alemanha (Parágrafo 90 A do BGB e parágrafo 811 do Código Processual Civil ZPO); da Suíça (artigos 641 e 651 A), da Áustria (artigo 285 A), da França (artigos 514-14, 524 e 528) e de Portugal (artigos 202 A), revelam que esse novo olhar deve ser alargado para outros ordenamentos jurídicos. ${ }^{12}$

O Código Civil brasileiro considera os animais como bens móveis, sujeitando-os ao regime jurídico das coisas (artigos 82 e 83). Os bens móveis são suscetíveis de movimento próprio (semoventes), ou de remoção por força alheia, sem alteração da substância ou da destinação econômico-social, sendo, por sua natureza, indivisíveis. Em razão de potencialidade orgânica da sua natureza, os animais, ao se reproduzirem, produzem frutos, subordinando-se a destinação desses frutos naturais ao princípio da gravitação jurídica e de todos os efeitos daí advindos, sempre na disciplina das coisas. ${ }^{13}$

Alguns exemplos dessa necessidade de mudança legislativa se revela nas decisões jurisprudenciais firmadas pelos juízes das Varas de Família quando instados a decidir disputas de guarda do animal de companhia do casal no processo de divórcio ou os juízes das Varas Cíveis, nas de ações de indenização por dano moral ajuizadas por seus proprietários, pela dor da perda ou do sofrimento do animal de estimação causadas por uma conduta ilícita, tem reconhecido o animal como ser sensível e, portanto, não apenas como "coisa", objeto de compra e venda, posse, ocupação, condomínio etc.

Essa nova forma de pensar não é atual. Immanuel Kant, por exemplo, vislumbrava os animais não-humanos como seres sencientes e, como tal, capazes de sentir dor e prazer. Entretanto, por faltar-lhes a razão, compreendia os animais como instrumentos do homem, recebendo proteção jurídica indireta. ${ }^{14}$

Peter Singer defende que alguns animais devem ter seus interesses (até direitos) tutelados (como o caso da gorila Sandra na Argentina, a quem a Justiça concedeu habeas corpus para libertá-la do zoológico de Buenos Aires, destinando-a ao Santuário de Sorocaba, em São Paulo) e lhes ser reconhecida personalidade (embora sejam animais não-humanos e portanto, não pessoa) porque "some non-human animals do show self-awareness and capacity of racionability". Animais como elefantes, golfinhos, papagaios reconhecem sua própria imagem quando submetidos ao teste do espelho. ${ }^{15}$

Recentemente, a ciência médica revelou que pombos podem detectar tecidos cancerígenos nas mamografias. Cientistas treinaram um grupo de pássaros para apontar a diferença entre tecido benigno e maligno. ${ }^{16}$

Nesse caminhar, David Favre, da Universidade de Michigan, firmou entendimento de que melhor seria atribuir aos animais um novo status jurídico: o de propriedade viva. ${ }^{17}$ Mas no final das contas, a alteração legislativa ocorrida nos Códigos Civis dos países europeus é tímida (embora um começo), mas necessária; a lei poderia atribuir personalidade aos animais 
(em particular os animais de companhia), como atribui às pessoas jurídicas (corporações, fundações, associações), ao anencéfalo e ao embrião nos primeiros meses, porque, como entende Peter Singer the principle of equal consideration of species do not aply only to humans. It aplies to all animals capable of feelling pain. Mas essa questão poderá ser objeto de um novo artigo, pois foge ao aqui proposto.

O que aproxima os animais dos seres humanos e os afasta das coisas, cabendo-lhes a titularidade de direitos, é o fato de terem vida, como afirma Alexandra Leitão, embora reconheça que a maioria da doutrina e da jurisprudência entenda que não há um "direito do animal", mas o dever do homem de respeitar os interesses dos animais a fim de protegêlos da violência cruel e gratuita. Esses deveres do homem só reflexamente protegem os interesses dos animais. ${ }^{18}$ Tal assertiva levou-a a propor uma terceira categoria jurídica, afirmando que os animais são sujeitos de Direito (e não apenas beneficiários reflexos de um conjunto de deveres que impõe aos humanos o dever de cuidado, de proteção das espécies, proibindo tratamentos cruéis). ${ }^{19}$

Outra hipótese, na visão de Leitão, seria introduzir nos Códigos Civis a dicotomia entre "coisas insensíveis" e "coisas sensíveis", com diferenciação de regime jurídico aplicável a cada uma. ${ }^{20}$

A Declaração Universal dos Direitos dos Animais (DUDA), aprovada pela UNESCO (1978) consagra aos animais um feixe de direitos: o direito à vida e à existência $\left(\operatorname{artigo~} 1^{\circ}\right)$; o direito a ser respeitado, não ser exterminado nem explorado $\left(\operatorname{artigo} 2^{\circ}\right.$ ) e o direito à integriade física (artigo $3^{\circ}$ ), o direito dos animais de companhia a uma duração de vida conforme sua longevidade natural e não serem abandonados (artigo $6^{\circ}$ ), sendo a morte de um animal sem necessidade (claro que não o abate de animais) biocídio, não como reflexo dos deveres do ser humano para com os animais, mas elencando-os como sujeitos de direito. ${ }^{21}$

Atualmente, a Lei 2015-177 de 16/2, alterou o artigo 515 do Codigo Civil francês para inserir o animal como ser sensível. A mudança da legislação francesa visou conciliar a lei e o valor afetivo do animal, harmonizando os códigos civil e rural, modernizando o direito, sem, contudo, criar uma categoria específica para os animais. Na visão das associações de defesa dos animais, como a Fundação Brigitte Bardot, houve uma evolução, mas não ainda a necessária "revolução". ${ }^{22}$

Na Alemanha, a proteção jurídica tanto dos animais como da natureza está inserida no artigo 20-A da Constituição, sendo que a lei civil, no parágrafo $90^{\circ}$-A do BGB disciplina que: Apenas os objetos corpóreos são coisas tal como definido em lei. Animais não são coisas. Eles são protegidos por estatutos especiais. Eles são regidos por regras que se aplicam às coisas, com a modificação necessária, sendo que os animais criados na esfera doméstica não são suscetíveis de penhora. ${ }^{23}$

Como não poderia ser diferente, houve alterações legislativas na Austria (artigo 285 A do ABGB Allegmeines Burgeliches Gesetzbuch) e na Suiça (art 641 CC), com a peculiaridade de que neste país, interpreta-se a disposição causa mortis beneficiando um animal, como sendo o ônus de cuidar desse animal. Em 2010, a Suiça abriu à discussão popular a possibilidade dos animais serem representados no tribunal por um advogado que tutelaria seus interesses, criando-se o cargo de "advogado dos animais", mas o referendum não foi aprovado, uma vez que $70,5 \%$ dos suíços votaram contra. ${ }^{24}$ 
Ainda na Suíça, em 2008, entrou em vigor lei que estipula que animais sociais, como periquitos e hamsters tem que ter um parceiro na gaiola. ${ }^{25}$

Na India, o juiz Manmohan Singh ao decidir o recurso da ONG People for Animals vs Md Mohazzim E Anr contra o confinamento de pássaros em gaiolas e venda com fins lucrativos disse textualmente que they deserve sympathy. (...) Birds have fundamental rights including the right to live with dignity and they cannot be subjected to cruelty by anyone. (..) Therefore, I am clear in mind that all the birds have fundamental rights to fly in the sky and all human beings have no right to keep them in small cages for the purposes of their business or otherwise. ${ }^{26}$

Castilla y Léon, cidade espanhola em que o abandono urbano dos animais de companhia é um grande problema, passou a disciplinar o seu comércio, editando a Ley $5 / 1997$ de $24 / 4 .^{27}$

Em Portugal, além da alteração havida no diploma civil, a Lei 110/2015 de 26 de agosto tipifica certas condutas lesivas praticadas contra os animais de companhia como crimes. ${ }^{28}$

O Brasil eleva a proteção animal a status constitucional, quando afirma que todos têm direito ao meio ambiente ecologicamente equilibrado, bem de uso comum do povo e essencial à sadia qualidade de vida, impondo-se ao Poder Público e à coletividade o dever de defendê-lo e preservá- lo para as presentes e futuras gerações. (artigo 225).

De sorte que incumbe ao Ministério Público, proteger a fauna e a flora, vedadas, na forma da lei, as práticas que coloquem em risco sua função ecológica, provoquem a extinção de espécies ou submetam os animais a crueldade. (artigo 225, parágrafo $1^{\circ}$ inciso VII, regulamentado pela Lei 11.794/08).

A Lei 9.605/98 disciplina o meio ambiente e tem um capítulo dirigido aos crimes contra o meio ambiente e uma seção acerca dos crimes contra fauna, punindo com detenção de três meses a um ano e multa aquele que praticar ato de abuso, maus-tratos, ferir ou mutilar animais silvestres, domésticos ou domesticados, nativos ou exóticos (artigo 32),

O Estado do Rio Grande do Sul, por sua vez, instituiu o Código Estadual de Proteção dos Animais (Lei 11.915/2003) com o objetivo de compatibilizar o desenvolvimento socioeconômico com a preservação animal.

Há uma gama de leis especiais impondo penas severas àqueles que maltratam animais, sendo tal conduta tipificada pelo Código Penal brasileiro como crime.

Embora haja a proteção constitucional e penal, o ramo do direito privado é incipiente quanto aos interesses dos animais. O Código Civil brasileiro considera que os animais são coisas, com regime jurídico dos bens móveis (semoventes) nos artigos 82 e 83, podendo ser objeto de propriedade, ocupação, compra e venda, posse e partilha em caso de divórcio, estando em dissonância com a evolução do pensamento jurídico atual, fundado em bases éticas e de consciência ambiental. Afinal, os animais não-humanos vivem e compartilham o mesmo ecossistema que os animais-humanos.

O Direito não é, nunca foi, e nunca poderá ser estanque; antes de mais nada, acompanha as mudanças sociais, adequa-se a novos padrões e ao avanço das ciências. De modo que alterar o Código Civil, como proposto pelo Deputado Antonio Anastasia (PL 351/15) é necessário e urgente. Talvez - e aí a assertiva fica apenas no campo das ideias a serem desenvolvidas em um outro artigo - poder-se-ia reconhecer personalidade jurídica aos animais. 
A neurociência, a biologia e etologia afirmam que animais não são coisas; são seres sencientes dotados de consciência. Marisa Quaresma dos Reis assevera que quando se discute a atribuição de direitos aos animais, pensa-se sobretudo nos cordados, em especial, nos mamíferos, aves e répteis. Ou seja: descarta-se qualquer direito a ser atribuído aos outros filos. Afinal, biologicamente são todos animais, mas nem todos juridicamente iguais. ${ }^{29}$

Fala-se em direitos, mas apenas para os animais mais próximos do ser humano.

Entretanto, deve-se garantir aos animais um estatuto jurídico compatível com sua natureza de coisa sensível, uma vez que maltratá-los degrada também a nossa humanidade. ${ }^{30}$

Afinal, o homem também é um animal. Nas palavras de Fernando Araujo:

"Eu não sei se alguém poderá ter dito isso dessa forma ou se não haverá aí um exagero caricatural: mas não há ninguém no mundo que não posssa defender os direitos pelo menos de um animal, que é o animal humano. Portanto, quando nós defendemos os direitos dos animais, os primeiros animais que nós defendemos são os homens. E as pessoas normalmente esquecem isso. É que a defesa dos animais não humanos é uma estratégia de reforço da defesa dos direitos dos animais humanos. Porque parte mais importante da nossa existência terrena é a preservação de nossos interesses, da nossa própria animalidade. Ou seja, nós não somos absolutamente nada senão produtos culturais que tem uma raiz animal. E se nós não respeitamos a nossa raiz animal, e a animalidade em nós, todo o resto desaparece e perde o seu significado. Muitas das coisas que nós defendemos como direitos humanos e que associamos tanto àquela formula, agora já muito esvaziada, da dignidade da pessoa humana, é a defesa de coisas que nós experimentamos e sofremos exclusivamente como animais. São defesas contra a morte violenta, contra a opressão, contra o medo, que são sentimentos que nós partilhamos com todos os outros animais e que não são traços distintivos da espécie humana. Basta-nos pensarmos um bocadinho sobre aquilo que nós defendemos quando defendemos a dignidade da pessoa humana para sabermos imediatamente o que estamos a lutar é pelos direitos dos animais. É verdade que a expressão normalmente é restrita aos animais não-humanos. Mas eu recusome a entrar nessa dicotomia, porque essa dicotomia já parece querer provar que nós temos alguma superioridade em matéria do nosso estatuto pertença cumulativos intelectuais e físicos do nosso planeta. Nós não estamos sozinhos no planeta e respiramos o mesmo ar, bebemos a mesma água e temos os mesmos alimentos que os animais não-humanos. Portanto, se é para vivermos todos no mesmo planeta, precisamos ter algum acesso básico a esses princípios". ${ }^{31}$

De modo que, a senciência é a capacidade dos seres vivos de sentir algo de foma consciente, ter sensações e sentimentos. $O$ animal é um ser senciente porque tem a capacidade de sentir, sendo a dor o sinal exterior mais significativo. Os animais são capazes de sofrer, embora não dotados de razão e por estarem no mesmo ecossistema que os animais-humanos, merecem especial proteção, ainda mais os animais de companhia.

A Convenção Europeia para a proteção dos animais de companhia (13 de novembro 1987) considera por animal de companhia qualquer animal possuído ou destinado a ser possuído pelo homem, designadamente em sua casa, para seu entretenimento e enquanto companhia, sendo proibido o treinamento do animal de forma prejudicial para a sua saúde 
ou seu bem-estar, forçando-o a exceder suas capacidades ou forças naturais. Ninguém deve inutilmente causar dor, sofrimento ou angústia a um animal de companhia, nem abandonálo.

Em Portugal, a Lei n. ${ }^{\circ}$ 69/2014, de 29 de agosto ao alterar o Código Penal, conceitua animal de companhia como qualquer animal detido ou destinado a ser detido por seres humanos, designadamente no seu lar, para seu entretenimento e companhia, não se aplicando a utilização de animais para fins de exploração agrícola, pecuária ou agroindustrial, assim como não se aplica a factos relacionados com a utilização de animais para fins de espetáculo comercial ou outros fins legalmente previstos (art. 389). Os maus-tratos a animais de companhia, disciplina no artigo $387^{\circ}$ as sanções para quem, sem motivo legítimo, infligir dor, sofrimento ou quaisquer outros maus-tratos físicos, bem como para quem abandona os animais, pondo em perigo a sua alimentação e os cuidados que lhe são devidos (art. 387 e 388).

Nos Estados Unidos, um órgão do governo, Americans with Disabilities Act (ADA), define e diferencia o que seria um animal de companhia que serve para suporte ou auxílio em algum aspecto físico ou emocional a indivíduos ou grupo familiar.

Há no Brasil a preocupação em conceder especial proteção aos animais de companhia, regulamentar a sua guarda em casos de divórcio e alterar o Código Civil para reconhecer as suas características de senciência e de autoreconhecimento (consciência), sendo a cidade de Porto Alegre pioneira ao criar a Delegacia dos Direitos dos Animais. ${ }^{32}$

Como dito anteriormente, a Constituição de 1988 veda de maneira clara o tratamento cruel aos animais e condena atos que possam levar à extinção dos mesmos. Mais recentemente, no Projeto de Lei do Senado n 351 de 2015, o senador Antônio Anastasia para efeitos legais incluiu explicitamente os animais no rol de bens móveis. Tal medida foi considerada como um grande passo para uma mudança de paradigma jurídico e, consequentemente, na sociedade no que tange a relação do homem com os animais.

A proposição acarreta, para efeitos legais, uma distinção dos animais de objetos comuns. A partir da aprovação desta lei, o animal passa a ser tratado como um tipo especial de bem, porque a lei o descreve como ser senciente, consequentemente, não pode ser tratado simplesmente como uma peça de mobília.

O neologismo senciente, vem da expressão senciência que é empregada para definir a capacidade dos seres de sentir algo de forma conscientemente. Ou seja, trata-se da capacidade dos animais serem sensível a tudo o que lhes acontece. Apesar de parecer algo que a primeira vista parece óbvio, tal capacidade é frequentemente questionada.

O motivo para isso reside no fato de sentimentos de modo geral sejam intrinsecamente subjetivos mesmo no homem. Como exemplo, como fazemos para termos certeza que uma pessoa realmente ama, sente frio, esta assustada, esta com medo ou odeia algo ou alguém? Avaliam-se sempre as consequências e sinais físicos dos sentimentos e nunca o sentimento em si. A mesma dificuldade é encontrada nos animais, somado à barreira da comunicação interespecífica.

Frequentemente tenta-se dissecar a senciência animal por meio de características humanas, seja treinando primatas não humanos para usar linguagem de sinais ou analisando a capacidade de animais fazerem fazer animais fazer aritmética. Historicamente, trata-se do motivo pelo qual desprezamos as emoções animais, pois não conseguimos reconhecer suas experiências emocionais ou consideramos que elas diferem muito das nossas e são de 
importância menor. Essa visão é equivocada por ser antropocêntrica.

Cientificamente falando a senciência animal não é uma teoria e sim um fato, pois muitos experimentos clássicos dependem da capacidade de ter percepções conscientes. ${ }^{33}$ Vários estudos de avaliação de analgesia, por exemplo, exigem partir do princípio que os animais sintam dor. Há também modelos animais de esquizofrenia, nos quais é testada uma série de emoções, como medo e ansiedade. ${ }^{34}$

A proposta de alteração legislativa citada ainda é tímida. Sem dúvida, a lei poderia atribuir personalidade aos animais, como atribui às pessoas jurídicas. Afinal, os cachorros usam a mesma parte do cérebro humano para sentir. Estudos de ressonância magnética funcional geraram mapas cerebrais que comprovaram que os cães usam a mesma parte do cérebro humano para prever situações prazerosas: o núcleo caudado. Essa área encefálica é rica em receptores de dopamina e se tona ativa diante de uma situação que envolve comida, amor e dinheiro para nós, seres humanos. A mesma região encefálica mostrou-se ativada em uma cadela quando simularam que ela receberia alimento ou quando o dono reapareceu após ter ficado por algum tempo ausente. ${ }^{35}$

À primeira vista pode parecer um exagero uma vez que os animais não expressam emoções com a fala. Todavia, segundo Gregory Berns, coautor do trabalho citado, também considerado um dos maiores especialistas da atualidade em cognição canina: "Se aceitarmos que bebês expressam emoções, então precisamos aceitar que animais também as têm. Não acho que a linguagem é necessária para sentir emoção." 36

A jurisprudência tem acompahado a evolução dos fatos sociais, inclusive do novo paradigma do Direito de Família, em que as famílias pós-modernas se constituem por outras formas que não o casamento: pela união estável, a família homoafetiva, monoparental, anaparental e, inclusive, a eudemonista. Todas elas caracterizadas pelo vínculo do afeto.

Não é raro que essas diversas formas de família agreguem ao convívio de seus membros um animal de companhia.

Em Jacareí, estabeleceu-se a guarda compartilhada de um cão entre os ex-cônjuges, fundamentando o juiz a sua decisão na interpretação de que o animal não é coisa, mas sujeito de direitos, não podendo ser vendido e a renda partilhada. ${ }^{37}$

A Décima Câmara de Direito Privado do Tribunal de Justiça de São Paulo determinou a guarda compartilhada de um cão aos ex-cônjuges, solucionando o conflito instaurado entre ambos pelo direito de visitas que foi negado à mulher. O Des. Relator, Carlos Alberto Garbi, foi incisivo: "É preciso, como afirma Francesca Rescigno, superar o antropocentrismo a partir do reconhecimento de que o homem não é o único sujeito de consideração moral, de modo que os princípios de igualdade e justiça não se aplicam somente aos seres humanos, mas a todos os sujeitos viventes" ${ }^{38}$

No Rio de Janeiro, a 22a Câmara Cível concedeu a guarda compartilhada de um cão aos ex-consortes por entender que há animais que participam e compõem efetivamente a família de seus donos, a ponto da sua perda ser extremamente penosa. No caso concreto, o varão havia dado o cão Dully à ex-mulher para ajudá-la a superar o aborto pelo qual passara. ${ }^{39}$

Essa mudança de paradigma fez com que um magistrado da Vara Cível de Joinville em Santa Catarina declinasse da competência em favor de uma das varas de família para decidir o conflito de posse e propriedade de um cadelinha de nome "Linda". ${ }^{40}$ 
Durante a realização do X Congresso Brasileiro de Direito de Família, foram aprovados os Enunciados Programáticos do Instituto Brasileiro de Direito de Família (IBDFAM), diretrizes para a criação da nova doutrina e jurisprudência em Direito de Família no Brasil. O Enunciado 11 reza que na ação destinada a dissolver o casamento ou a união estável, pode o juiz disciplinar a custódia compartilhada do animal de estimação do casal. ${ }^{41}$

Mas não é apenas no Direito de Família que essa mudança tem se revelado, sendo significativo o novo papel do animal de companhia nas famílias modernas, que passa a ser considerado como verdadeiro membro da família. Dimitre Braga Soares diz que pesquisas apontam que em torno de $30 \%$ dos donos de animais os consideram parte da família e são verdadeiros companheiros das pessoas que vivem sozinhas, quase como filhos. Não é a toa que $45 \%$ dos lares brasileiros tem algum animal de estimação. ${ }^{42}$

Nessa toada, propostas de lei surgem para disciplinar a questão. O Projeto de Lei 1.365 de maio de 2015 de autoria de Ricardo Tripoli dispõe sobre a guarda dos animais de estimação nos casos de dissolução litigiosa da sociedade e do vínculo conjugal entre seus possuidores e, em não havendo consenso, a guarda deve ser atribuída àquele que demonstrar maior vínculo afetivo com o animal e maior capacidade para o exercício da posse responsável. O juiz deverá observar qual dos divorciandos pode oferecer ao animal ambiente adequado para a morada, disponibilidade de tempo, condições de trato, de zelo e de sustento; o grau de afinidade e afetividade entre o animal e a parte. Se o juiz verificar que o animal de estimação não deverá permanecer sob a guarda de nenhum de seus detentores, deferi-la-á pessoa que revele compatibilidade com a natureza da medida, consideradas as relações de afinidade e afetividade dos familiares, bem como o local destinado para manutenção de sua sobrevivência. A parte que contrair nova união não perde o direito de ter consigo o animal de estimação, que só lhe poderá ser retirado por mandado judicial, provado que não está sendo tratado convenientemente ou em desacordo com as cláusulas, conforme despacho do juiz.

A Eposição de Motivos do Projeto ressalta que inúmeros são os casos em que esses animais de estimação são criados quase como filhos pelo casal, incluíndo-os no rol dos bens a serem partilhados de acordo com o que ditar o regime de bens do casal.

O Projeto de Lei 3.835/15 de Goulart, que está apensado ao PL 1.365/15, conceitua os animais de estimação como aquelas espécies domésticas ou domesticadas, mantidos em cativeiro pelo homem, capazes de estabelecerem o convívio e a coabitação, sem o propósito de abate (art. 3º. Há ainda o PL 7.196/10 proposto pelo Deputado Márcio França, arquivado, mas cujo objeto era o mesmo dos acima citados.

Na França, exemplo dessa evolução recepcionada pelo Código Civil daquele país, foi a decisão judicial que desconsiderou a aplicação do Código do Consumidor a um contrato de compra e venda e não permitiu a devolução de um cachorrinho de companhia que apresentava problemas de visão ao vendedor.

A Corte de Cassação aplicou o artigo 515-14 do Código Civil fundamentando que o cachorro em questão é um ser vivo, único e insubstituível, é um animal de companhia destinado a receber afeto de seu dono: "le chien en cause était un être vivant, unique et irremplaçable, et un animal de compagnie destiné à recevoir l’affection de son maître, sans aucune vocation économique" ${ }^{43}$ 
Entretanto, não faltam decisões judiciais que interpretam de modo diverso esse fenômeno jurídico-social. Em São Paulo, foi impetrado mandado de segurança objetivando a concessão de medicamento de alto custo pelo Sistema Único de Saúde (SUS) para uma cachorra da raça Golden retriver. Entendeu a juíza que não há dúvidas de que um cachorro, ou qualquer outro animal, não tem capacidade para ser parte em mandado de segurança, nem tampouco de pleitear medicamentos. ${ }^{44}$

O Tribunal Regional Federal da 3a Região, tratou de tema semelhante, negando habeas corpus impetrado em favor de um chimpanzé. (Habeas Corpus no 000263770.2010.8.19.0000)

De modo que as alterações propostas no Projeto de Lei 315/15 do Deputado Antonio Anastasia $^{45}$ para alterar o Código Civil Brasileiro são de extrema relevância, para que se acompanhe a tendência dos países europeus e se faça cumprir a Constituição Federal e os princípios éticos, não mais calcados no antropocentrismo, outorgando aos animais, em especial aos animais de companhia, o status de seres sencientes, capazes de sentir dor e prazer.

\section{CONSIDERAÇÕES FINAIS}

Os animais são seres vivos e sensíveis à dor, maus-tratos, violência, não podendo hodiernamente receber o mesmo tratamento jurídico dos bens e, por isso, são merecedores de proteção de seus interesses, quiçá serem dotados de um estatuto jurídico que discipline a sua natureza e reconheça suas diferenças, não apenas em face dos seres humanos, mas também em relação às coisas.

A evolução da ética e bioética, da consciência ambiental, do pensamento filosófico, social e jurídico impõe que seja alterado o Código Civil brasileiro, como proposto no Projeto de Lei 315/15.

Os animais não podem mais ser considerados coisas, como uma peça de mobiliário, objeto de bem de consumo, devendo ter status diferenciado justamente por terem vida, sentirem dor, embora em princípio não se possa dotá-los de personalidade, considerá-los como sujeito de direitos. Mas seus interesses não podem mais ser defendidos de modo indireto quando se defendem os interesses do homem.

Evidente a sua importância, até porque o animal de companhia alçou a posição de membro da família. O novo paradigma de família, baseada no afeto, permite afirmar que o animal de companhia é acolhido como pertencendo ao núcleo familiar e, por conseguinte, não pode ser alienado e o produto da venda partilhado entre os ex-cônjuges. O juiz, sensível a essa evolução, deverá conceder a guarda compartilhada do animal ou, então, a guarda unilateral àquele que tiver melhores condições de prover seus cuidados.

A jurisprudência tem acompahado a evolução dos fatos sociais, em que as famílias pós-modernas se constituem por outras formas que não o casamento: pela união estável, a família homoafetiva, monoparental, anaparental e, inclusive, a eudemonista. Todas elas caracterizadas pelo vínculo do afeto. Não é raro que essas diversas formas de família agreguem ao convívio de seus membros um animal de companhia. 
As decisões judiciais na esfera cível, nas ações de indenização por dano material e moral, ou nas relações de compra e venda de animais de companhia, tem acompanhado essa tendência.

De forma que, ao respeitarmos os animais-não humanos, promovemos o bem comum, convivendo em um ecossistema equilibrado, sem impingir violência ou dor a outro ser vivo. Ao atribuir novo status ao animal como ser senciente, alçamos o princípio da dignidade humana ao patamar de proteção de todos os homens.

\section{Notas}

1 FARACO, C. B.; SEMINOTTI, N., A Relação Homem-Animal e a Prática Veterinária. Revista CFMV, Vol. 10, N. 32, p. 57-62. 2004

2 SERPELL, J. A. "Childhood Pet keeping and Humane Attitudes in Young Adulthood", Animal Welfare, 1993, Vol.1, N. 2, p. 321-337.

3 TRUT, L.; OSKINA, I.; KHARLAMOVA, A. Animal evolution during domestication: the domesticated fox as a model. Bioessays. 2009 Mar; 31(3): 349-360.

4 SERPELL, J. A., “Childhood Pet keeping and Humane Attitudes in Young Adulthood”

5 COSTA, E. C. Animais de estimação: uma abordagem psico-sociológica da concepção dos idosos (Dissertação de Mestrado em Saúde Pública). Universidade Estadual do Ceará, Fortaleza. 2006.

6 BEETZ, A.;UVNÄS-MOBERG,K.;JULIUS,H.; KOTRSCHAL, K. Psychosocial and Psychophysiological Effects of Human-Animal Interactions: The Possible Role of Oxytocin. Front Psychol. 2012; 3: 234.

7 GIUMELLI, R.D.; SANTOS, M.C.P. Convivência com Animais de Estimação: Um Estudo Fenomenológico. Revista da Abordagem Gestáltica - Phenomenological Studies - XXII(1): 49-58, janjun, 2016; TATIBANA, L. S. \& COSTA-VAL, A. P. Relação homem-animal de companhia e o papel do médico veterinário. Revista Veterinária e Zootecnia em Minas, 2009, n. 103.

8 GIUMELLI, R.D.; SANTOS, M.C.P. Convivência com Animais de Estimação: Um Estudo Fenomenológico, p.49-58

9 DA MATTA, Roberto. O que faz o brasil, Brasil? Rio de Janeiro: Rocco, 1986 p. 27

${ }^{10}$ ABINPET. Associação Brasileira da Indústria de Produtos para Animais de Estimação (2014). Disponível em http:/ / abinpet.org.br/site/ <Acesso em 3/03/2017>

11 VIVALDINI, V. H. Terapia Assistida por Animais: Uma aborgadem lúdica em Reabilitação clínica de pessoas com deficiência intelectual (Dissertação de mestrado em Psicologia da Saúde). Universidade Metodista de São Paulo, São Bernardo do Campo. 2011

12 As alterações do Codigo Civil Português estão nos artigos $202^{\circ}$ A (o animal é ser sensível e digno de proteção por lei especial), artigo $205^{\circ}$, artigo $496^{\circ}$ A (o valor da indenização deve incluir o valor da afeição em caso de lesão ou morte do animal,), artigo $1305^{\circ}$ A, artigo $1302^{\circ}$ A, artigos 1321, 1323, 1318 e 1323 (desconsideração dos animais como coisa móvel) e, por fim, artigo 1775 (destinação do animal de companhia em caso de divórcio). 
13 GONÇALVES, Carlos Roberto. Direito civil esquematizado. São Paulo: Saraiva, 2012 V 1-2 p. 231 a 247

14 Os Animais: Sujeitos De Direito Ou Direitos De Um Sujeito? Dissertação apresentada à Faculdade de Direito da Universidade de Coimbra no âmbito do 2. ${ }^{\circ}$ ciclo de Estudos em Direito (conducente ao grau de mestre), na Área de Especialização em Ciências Jurídico-Forenses. Orientadora: Professora Doutora Maria Olinda Garcia. Coimbra, 2015.

15 Personhood beyond the human: Peter Singer Keynote Adres

16 http://www.dailymail.co.uk/sciencetech/article-3323946/The

PIGEON-Birds-spot-canceroustissue-mammograms-humans.html <Acesso em 28/03/2017>

17 FAVRE, David. A proriedade viva: um novo status pra os animais dentro do sistema jurídico. Revista Brasileira de Direito Animal. p. 101 a 175 Ano 6 vol 9 jul-dez 2011

18 LEITÃO, Alexandra. Os espetáculos e outras formas de exibição de animais. p. 17 In: DUARTE, Maria Luísa GOMES, Carla Amado (Coord) Direito (do) Animal. Coimbra: Almedina, 2016. 346 p

$19 \quad$ Ibid, p. 18.

$20 \quad$ Ibid, p. 19.

21 Ibid, p. 20.

22 www.portugues.rfi.fr/fram \nca/20140416-mudanca-no-xondigo-civil-frances.

23 Código de Processo Civil da Alemanha (Zivilprozessordnug) parágrafo 811

24 DOS REIS, Marisa Quaresma. O papel da ciência na ascensão do Direito Animal e no reconhecimento de direitos dos animais - uma perspectiva comparatista. p. 216 In: DUARTE, Maria Luísa GOMES, Carla Amado (Coord) Direito (do) Animal. Coimbra: Almedina, 2016. 346 p

25 Ibid, p. 216

$26 \quad$ Ibid, p. 219

27 Art $2^{\circ}$ Son animales de compañía los animales domésticos o domesticados, a excepción de los de renta y de los criados para el aprovechamiento de sus producciones, siempre y cuando a lo largo de su vida se les destine única y exclusivamente a este fin. file:///Users/joao/Downloads/37633481_118_DOCSLEG_LCyL_1997_147. dat.pdf <Acesso em 7/03/2017>

28 EGÍDIO, Mariana Melo. Criação de animais de companhia p. 157 In: DUARTE, Maria Luísa GOMES, Carla Amado (Coord) Direito (do) Animal. Coimbra: Almedina, 2016. 346 p

29 DOS REIS, Marisa Quaresma. O papel da ciência na ascensão do Direito Animal e no reconhecimento de direitos dos animais - uma perspectiva comparatista. p. 261 In: DUARTE, Maria Luísa GOMES, Carla Amado (Coord) Direito (do) Animal. Coimbra: Almedina, 2016. 346 p

30 NEVES, Helena Telino. Personalidade jurídica e direitos para quais animais? In: DUARTE, Maria Luísa GOMES, Carla Amado (Coord) Direito (do) Animal. Coimbra: Almedina, 2016. 346 p

31 Conforme transcrição livre das palavras de Fernando Araújo. Excerto da intervenção do Professor 
Fernando Araújo no Seminário Teoria da Decisão Judicial - A Justificação das Decisões Judiciais. Neste excerto, o Professor Catedrático da Faculdade de Direito da Universidade de Lisboa fala sobre Direitos dos Animais ao responder uma questão da platéia. Disponivel em https://www.youtube. com/watch?v=2zD5oPNeiQc <Acesso em 17/03/2017>

32 http://www2.portoalegre.rs.gov.br/seda/default.php?p_noticia=164765\&PORTO+ALEGRE+TERA+DELEGACIA+ESPECIALIZADA+NA+PROTECAO+DOS+ANIMAIS <Acesso em 20/03/2017>

33 BURGDORF J., PANKSEPP J. The neurobiology of positive emotions. Neurosci. Biobehav. Rev. 2006;30:173-87. doi: 10.1016/j.neubiorev.2005.06.001

34 Ibiden

35 COOK PF, PRICHARD A, SPIVAK M, BERNS GS. Awake canine fMRI predicts dogs' preference for praise vs food. Soc Cogn Affect Neurosci. 2016 Dec;11(12):1853-1862. Epub 2016 Aug 12.

36 BERNS, G. 2016. REVISTA CIÊNCIA HOJE / EDIÇÃO 336. Imagens da Mente Canina. http:/ / www. cienciahoje.org.br/revista/materia/id/1031/n/imagens_da_mente_canina <Acesso em 2/2/2017>

37 < http://www.ibdfam.org.br/noticias/5905/Justi\%C3\%A7a+de+SP+determina+guarda+compartilh ada+de+animal+de+estima $\% \mathrm{C} 3 \% \mathrm{~A} 7 \% \mathrm{C} 3 \% \mathrm{~A} 3 \mathrm{o}+$ durante+processo+de+div $\% \mathrm{C} 3 \% \mathrm{~B} 3 \mathrm{rcio}<\mathrm{Acesso}$ em $24 / 02 / 2017>$

$38 \mathrm{ht} \mathrm{tp://www.ibdfam.org.br/n} \mathrm{oticias} \mathrm{/} \mathrm{n} \mathrm{a} \mathrm{midia/} 10654 /$ TJSP+autoriza+guarda+alternada+de+animal+de+estimação <Acesso em 10/04/2017>

39 http://www.ibdfam.org.br/noticias/na-midia/9384 <Acesso em 20/05/2017>

40 http://www.ibdfam.org.br/noticias/6004/Magistrado+considera+cadela+criatura+senciente+e+declina+compet $\%$ C3\% AAncia+sobre+processo+de+posse+para+vara+de+fam \%C3\% ADlia

41 http://www.ibdfam.org.br/favoritar/noticias/5819/IBDFAM+aprova+Enunciados+++

42 Dimitre Braga Soares é mestre em Direito pela UFPB. Professor Assistente I de Direito Civil da UFRN. Vice-Presidente do IBDFAM-PB. Advogado familiarista. Contato: dimitresoares@hotmail.com Animais de Estimação e Direito de Família. Disponivel em http://www.ibdfam.org.br/favoritar/ artigos/531/Animais+de+Estima \%C3\%A7\%C3\%A3o+e+Direito+de+Fam\%C3\%ADlia <Acesso em $22 / 5 / 2017>$

43 Artigo de Marie Coquil intitulado L'animal de compagnie vendu est-il remplaçable en cas de défaut de conformité ? Nouvel éclairage sur le régime juridique de l'animal. Disponivel em. https://www. legifrance.gouv.fr/affichCodeArticle.do;jsessionid=C7CC1C511FE3A086A8381F366AEBF512. tpdjo06v_3?idArticle=LEGIARTI000022200245\&cidTexte=LEGITEXT000006071367 <Acesso em 02/03/2017> Tradução livre: o cahorro em questão é um ser vivo, único e insubstituível, e um animal de companhia destinado a receber a afeição de seu dono, sem nenhuma vocação econômica.

BRASIL. Tribunal de Justiça do Estado de São Paulo. Processo Digital n ${ }^{\mathrm{o}}: 1024679-29.2016 .8 .26 .00531^{\text {a }}$ Vara da Fazenda Publica Classe - Assunto Mandado de Segurança -Fornecimento de Medicamentos Impetrante:Jaqueline Dias Costa Impetrado: Secretario de Saude do Estado de São PauloJuiz(a) de Direito: Dr(a). Juliana Morais Bicudo.

45 BRASIL. SENADO FEDERAL. Projeto de Lei do Senado PLS 315/2015. Altera a Lei $n^{\circ} 10.406$, de 10 de janeiro de 2002 (Código Civil), para determinar que os animais não sejam considerados coisas, mas bens móveis para os efeitos legais, salvo o disposto em lei especial. O Congresso Nacional decreta: 
Art. $1^{\circ}$ A Lei $\mathrm{n}^{\mathrm{o}}$ 10.406, de 10 de janeiro de 2002 (Código Civil), passa a vigorar com as seguintes alterações: "Art. 83. IV - os animais, salvo o disposto em lei especial. Parágrafo único. Os animais não serão considerados coisas." (NR) "Art. 1.313. II - apoderar-se de coisas suas, bem como de animais que aí se encontrem casualmente. $\S 2^{\circ} \mathrm{Na}$ hipótese do inciso II, uma vez entregues as coisas ou os animais buscados pelo vizinho, poderá ser impedida a sua entrada no imóvel." (NR) Art. $2^{\circ}$ Esta Lei entra em vigor na data de sua publicação. Senado Federal, em 18 de novembro de 2015. Senador Renan Calheiros Presidente do Senado Federal

\section{REFERÊNCIAS BibLIOGRÁFICAS}

ABINPET. Associação Brasileira da Indústria de Produtos para Animais de Estimação. 2014. Disponível em http://abinpet.org.br/site/

ADA BUSINESS BRIEF:SERVICE ANIMALS. U.S. Department of Justice. Civil Rights Division - Disability Rights Sectionhttps://www.ada.gov/svcabrs3.pdf

ARAUJO, Fernando. Seminário Teoria da Decisão Judicial - A Justificação das Decisões Judiciais Excerto em resposta a uma questão da platéia. Disponivel em https://www.youtube.com/watch?v=2zD5oPNeiQc

BEETZ, A.; UVNÄS-MOBERG,K.; JULIUS, H.; KOTRSCHAL, K. Psychosocial and Psychophysiological Effects of Human-Animal Interactions: The Possible Role of Oxytocin. Front Psychol. 2012; 3: 234.

BERNS, G. Imagens da Mente Canina. Revista Ciência Hoje Edição 336. 2016. Disponivel em http:// www.cienciahoje.org.br/revista/materia/id/1031/n/imagens_da_mente_canina

BRASIL. CAMARA DOS DEPUTADOS. Projeto de lei PL 1365/15. PSDB/SP. Ricardo Tripoli. Dispõe sobre a guarda dos animais de estimação nos casos de dissolução litigiosa da sociedade e do vínculo conjugal entre seus possuidores, e dá outras providências.

BRASIL. CAMARA DOS DEPUTADOS. Projeto de Lei PL 7196/10. Márcio França. PSB/SP. Dispõe sobre a guarda dos animais de estimação nos casos de dissolução litigiosa da sociedade e do vínculo conjugal entre seus possuidores, e dá outras providências.

BRASIL. SENADO FEDERAL. Projeto de Lei do Senado PLS 315/2015. Acrescenta parágrafo único ao art. 82, e inciso IV ao art. 83 da Lei ${ }^{\circ}$ 10.406, de 10 de janeiro de 2002 (Código Civil), para que determinar que os animais não serão considerados coisas.

BRASIL. SENADO FEDERAL. Projeto de Lei do Senado PL 1058/11. Dr. Ubiali - PSB/SP. Proposta prevê regras para a guarda de animal em caso de divórcio.

BRASIL. Tribunal de Justiça do Estado de São Paulo. Processo Digital nº:1024679-29.2016.8.26.0053 $1^{\text {a }}$ Vara da Fazenda Pública Classe - AssuntoMandado de Segurança -Fornecimento de Medicamentos Impetrante:Jaqueline Dias Costa Impetrado: Secretario de Saude do Estado de São PauloJuiz(a) de Direito: Dr(a). Juliana Morais Bicudo.

BURGDORF J., PANKSEPP J. The neurobiology of positive emotions. Neurosci. Biobehav. Rev. 2006;30:173-87. doi: 10.1016/j.neubiorev.2005.06.001.

COOK PF, PRICHARD A, SPIVAK M, BERNS GS. Awake canine fMRI predicts dogs' preference for praise vs food. Soc Cogn Affect Neurosci. 2016 Dec;11(12):1853-1862. Epub 2016 Aug 12.

COQUIL, Marie L'animal de compagnie vendu est-il remplaçable en cas de défaut de conformité ? Nouvel éclairage sur le régime juridique de l'animal. Disponivel em https://www. 
legifrance.gouv.fr/affichCodeArticle.do;jsessionid=C7CC1C511FE3A086A8381F366AEBF512. tpdjo06v_3?idArticle=LEGIARTI000022200245\&cidTexte=LEGITEXT000006071367.

COSTA, E. C. Animais de estimação: uma abordagem psico-sociológica da concepção dos idosos (Dissertação de Mestrado em Saúde Pública). Universidade Estadual do Ceará, Fortaleza. 2006.

DA MATTA, Roberto. O que faz o brasil, Brasil? Rio de Janeiro: Rocco, 1986.

DOS REIS, Marisa Quaresma. O papel da ciência na ascensão do Direito Animal e no reconhecimento de direitos dos animais - uma perspectiva comparatista. In DUARTE, Maria Luísa GOMES, Carla Amado (Coord) Direito (do) Animal. Coimbra: Almedina, 2016. 346 p

EGÍDIO, Mariana Melo. Criação de animais de companhia p. 157 In DUARTE, Maria Luísa GOMES, Carla Amado (Coord) Direito (do) Animal. Coimbra: Almedina, 2016. 346 p.

FARACO, C. B.; SEMINOTTI, N., A Relação Homem-Animal e a Prática Veterinária. Revista CFMV. 2004, Vol. 10, N. 32, p. 57-62.

GAETA, Alexandre. O código de direito animal. São Paulo: Madras Edtora Ltda, 2003.

GARCIA, Maria (Coord) Revista de Direito Constitucional e Internacional Ano 23 vol 93 out-dez/2015 Thomson Reuters Revista dos Tribunais São Paulo

GIUMELLI, R.D.; SANTOS, M.C.P. Convivência com Animais de Estimação: Um Estudo Fenomenológico. Revista da Abordagem Gestáltica - Phenomenological Studies - XXII(1): 49-58, jan-jun, 2016.

LEIS, Maria Fernanda. A influência do tratamento cruel aos animais domésticos no patrimônio cultural imaterial brasileiro. Dissertação de mestrado. Orientadora Profa. Maria Helena Diniz. Pontificia Universidade Catolica de São Paulo 2002.

LEITÃO, Alexandra. Os espetáculos e outras formas de exibição de animais. In DUARTE, Maria Luísa GOMES, Carla Amado (Coord) Direito (do) Animal. Coimbra: Almedina, 2016. 346 p.

LEVI, Primo. É Isto um Homem? Tradução de Luigi Del Rei. Rio de Janeiro: Rocco, 1988.

NEVES, Helena Telino. Personalidade jurídica e direitos para quais animais? In DUARTE, Maria Luísa GOMES, Carla Amado (Coord) Direito (do) Animal. Coimbra: Almedina, 2016. 346 p.

PUCCI, Luisa Léia Jacintho; LEHFELD, Lucas de Souza. A dignidade das futuras gerações ante a Constituição ambiental: a natureza como sujeito de direitos. Revista de Direito Constitucional e Internacional. Vol. 93 ano 23 p 103-118. São Paulo: Ed. RT, out-dez 2015.

SERPELL, J.A., "Childhood Pet keeping and Humane Attitudes in Young Adulthood", Animal Welfare, 1993, Vol.1, N. 2, p. 321-337.

SINGER, Peter. Animal liberation. New York: PS TM Harper Collins Publishers, 2009.

TATIBANA, L. S. \& COSTA-VAL, A. P. Relação homem-animal de companhia e o papel do médico veterinário. Revista Veterinária e Zootecnia em Minas, 2009, n. 103.

TRUT, L.; OSKINA,I.; KHARLAMOVA, A. Animal evolution during domestication: the domesticated fox as a model. Bioessays. 2009, Mar; 31(3): 349-360.

VIVALDINI, V. H. Terapia Assistida por Animais: Uma aborgadem lúdica em Reabilitação clínica de pessoas com deficiência intelectual (Dissertação de mestrado em Psicologia da Saúde). Universidade Metodista de São Paulo, São Bernardo do Campo. 2011. 